\title{
Depression, anxiety, stress, social interaction and health-related quality of life in men and women with unexplained chest pain Annika Janson Fagring ${ }^{* \dagger 1}$, Karin I Kjellgren ${ }^{\dagger 1}$, Annika Rosengren ${ }^{\dagger 2}$, Lauren Lissner ${ }^{3}$, Karin Manhem ${ }^{4}$ and Catharina Welin ${ }^{\dagger 1}$
}

\author{
Address: ${ }^{1}$ The Sahlgrenska Academy at Göteborg University, Institute of Health and Care Sciences, Göteborg, Sweden, ${ }^{2}$ Department of Medicine, \\ Sahlgrenska University Hospital/Östra, Göteborg, Sweden, ${ }^{3}$ Department of Community Medicine and Public Health/Epidemiology, the \\ Sahlgrenska Academy, Göteborg University, Sweden and 4Department of Medicine, Sahlgrenska University Hospital/Mölndal, Göteborg, Sweden \\ Email: Annika Janson Fagring* - annika.janson-fagring@gu.se; Karin I Kjellgren - karin.kjellgren@gu.se; \\ Annika Rosengren - annika.rosengren@gu.se; Lauren Lissner - lauren.lissner@medfak.gu.se; Karin Manhem - karin.manhem@vgregion.se; \\ Catharina Welin - catharina.welin@gu.se \\ * Corresponding author †Equal contributors
}

Published: 19 May 2008

BMC Public Health 2008, 8:165 doi:10.1/86/147|-2458-8-165

This article is available from: http://www.biomedcentral.com/147I-2458/8/165

(C) 2008 Fagring et al; licensee BioMed Central Ltd.

This is an Open Access article distributed under the terms of the Creative Commons Attribution License (http://creativecommons.org/licenses/by/2.0), which permits unrestricted use, distribution, and reproduction in any medium, provided the original work is properly cited.
Received: 22 January 2008

Accepted: 19 May 2008

\begin{abstract}
Background: Unexplained chest pain (UCP) is a common reason for emergency hospital admission and generates considerable health-care costs for society. Even though prior research indicates that psychological problems and impaired quality of life are common among UCP patients, there is lack of knowledge comparing UCP patients with a reference group from the general population. The aim of this study was to analyse differences between men and women with UCP and a reference group in terms of psychosocial factors as depression, anxiety, stress, social interaction and health-related quality of life (HRQOL).
\end{abstract}

Methods: A self-administered questionnaire about psychosocial factors was completed by 127 men and 104 women with acute UCP admitted consecutively to the Emergency Department (ED) or as in-patients on a medical ward. A reference group from the general population, 490 men and 579 women, participants in the INTERGENE study and free of clinical heart disease, were selected.

Results: The UCP patients were more likely to be immigrants, have a sedentary lifestyle, report stress at work and have symptoms of depression and trait-anxiety compared with the reference group. After adjustment for differences in age, smoking, hypertension and diabetes, these factors were still significantly more common among patients with UCP. In a stepwise multivariate model with mutual adjustment for psychosocial factors, being an immigrant was associated with a more than twofold risk in both sexes. Stress at work was associated with an almost fourfold increase in risk among men, whereas there was no independent impact for women. In contrast, depression only emerged as an independent risk factor in women. Trait-anxiety and a low level of social interaction were not independently associated with risk in either men or women. Patients with UCP were two to five times more likely to have low scores for HRQOL.

Conclusion: Both men and women with UCP had higher depression scores than referents, but an independent association was only found in women. Among men, perceived stress at work emerged as the only psychosocial variable significantly associated with UCP. 


\section{Background}

Unexplained chest pain (UCP) is a common reason for emergency hospital admission and generates considerable health-care costs for society $[1,2]$. Previous studies have often defined UCP as non-cardiac, i.e. chest pain that had not been diagnosed as acute myocardial infarction (AMI) or ischemic heart disease (IHD) by a physician [3]. Galmiche et al [4], has developed three diagnostic criteria for functional chest pain of presumed esophageal origin i.e. "1) Midline chest pain or discomfort that is not of burning quality. 2) Absence of evidence that gastroesophageal reflux is the cause of the symptom. 3) Absence of histopathology-based esophageal motility disorders" (p. 1461). Psychological factors e.g. anxiety and somatisation disorders will also have an impact on the functional chest pain. However, Fox [5] stresses that the terminology "unexplained chest pain", i.e. chest pain, which after investigation has proven to be unrelated to the heart, might be confusing but is still preferable to "non-cardiac" or "atypical chest pain".

Keogh et al. [6] reported that women with high anxiety sensitivity report more chronic pain than women with low anxiety sensitivity. No similar relationship was found for men. Gender differences are also seen in the diagnosis of chest pain, with male patients more likely than women to be diagnosed with cardiac chest pain instead of noncardiac chest pain [6], in accordance with their higher overall risk of IHD.

Studies of patients with a non-cardiac/non-coronary diagnosis of chest pain often include patients with other defined causes of chest pain, e.g. gastro-esophageal and musculoskeletal disorders [7]. However, a considerable number of the patients with a non-cardiac/coronary diagnosis do not have a clearly defined explanation for their chest pain.

Psychological problems are often reported in patients with unexplained chest pain. In a study of predictors of health-care seeking among non-cardiac chest pain patients, Eslick et al. [3] found that the main reason for seeking care was anxiety, with $78 \%$ of patients with noncardiac chest pain having sought health care in the last 12 months. Previous qualitative studies in UCP patients have found that the physical, psychological and social consequences of chest pain disturbed and negatively affected the patient's daily life $[8,9]$.

Even though prior research indicates that psychological problems and impaired quality of life are common among UCP patients, there is lack of knowledge comparing UCP patients with a reference group from the general population. Because psychological symptoms are prevalent also among the general population, comparing UCP patients and a reference group might improve knowledge of the importance of these factors in the increasingly large group of patients suffering from UCP.

The aim of the present study was to analyse differences between men and women with UCP and a reference group in terms of psychosocial factors as depression, anxiety, stress and health-related quality of life (HRQOL).

\section{Methods}

The study was carried out at Sahlgrenska University Hospital in Göteborg, Sweden. The study was approved by the Ethics Committee at Göteborg University, Sweden (study code 169-02), and was carried out in accordance with the Declaration of Helsinki.

\section{Study sample, setting and procedure The patients}

Data were collected during office hours, Monday through Friday, from December 2002 to September 2003. Patients between 25-69 years of age, who were 1) evaluated for acute chest pain and judged by a physician to have no organic cause of their chest pain and 2) free from any history of heart disease were considered for inclusion in the study. In all, 648 patients with UCP were eligible at ED during the study period. However, because patients could only be investigated during office hours and not during holidays or weekends only 337 patients were considered for inclusion during the study period. Patients who were too ill to participate $(n=4)$ or had language difficulties ( $\mathrm{n}$ = 37) were excluded. Eighteen patients declined to participate and 47 could not be investigated for administrative reasons (e.g. an overcrowded ED). In all, 231 patients (127 men and 104 women) took part in the study (78\%). Of these 157 were investigated in the ED and the remainder $(\mathrm{n}=74)$ after being admitted to a medical ward for further investigation. The results of the cardiac investigation were not known to the patient at the time of the interview. All the eligible patients were assessed and treated according to the routines of the ED. They were asked about participation by the investigators, thereafter written and verbal information about all the steps in the study was provided. After written informed consent was obtained, the patients filled in a questionnaire providing background characteristics and data on psychosocial factors, before being discharged. The ED patients filled in the questionnaire shortly after arrival in hospital, the inpatients within 24 hours after arrival.

\section{The reference group}

Residents of Göteborg aged 25-69 years and free of clinical heart disease were recruited from the INTERGENE study. INTERGENE is a population-based study assessing the interplay between genetic susceptibility, environmental factors, lifestyle and psychosocial background as risk 
factors for chronic diseases and cardiovascular disease. The reference group consisted of all the participants in the INTERGENE study. Of the recruited sample $(\mathrm{n}=2,422)$, $1,477(61 \%)$ came to the screening during the study period. Of these, 28 (17 men and 11 women) with previous MI/angina were excluded. Episodes (current or former) of chest pain were not investigated. The HRQOL and psychosocial questionnaires were introduced in a secondary survey of participants in the primary survey. For this reason, 380 people (189 men and 191 women) did not complete the questionnaires because they did not participate in the secondary survey. In all, 1,069 individuals (490 men and 579 women) participated (74\% of those screened without previous MI/angina). The reference participants were assessed according to the protocol for the INTERGENE study [10]. The psychological assessment was conducted after the basic examination.

\section{Measurements}

All the scales measuring psychosocial factors and HRQOL [11-15], are presented in Table 1. Perceived stress at work was assessed with one item (response alternatives; (0) never perceived stress, (1) some period of stress, (2) some period of stress during the last five years, (3) several periods of stress during the last five years, (4) permanent stress during the last year, (5) permanent stress during the last five years).

The patients' perception of their marriage or cohabitation was assessed with two items, i.e. "How do you perceive your marriage or cohabitation?" (response alternatives; (1) very happy, (2) fairly happy, (3) difficult to say, (4) rather unhappy, (5) very unhappy; summery score: $2-10$ ), and "How often do you have difficulty getting along with your wife or husband or cohabitant?" (response alternatives; (1) never, (2) seldom, (3) sometimes, (4) very often, (5) almost all the time; summery score 2-10) [16].

Demographics and background characteristics from the questionnaire were recorded from both the UCP patients and the reference group members regarding age; marital status (single, married/cohabitating, divorced, widow/er); education (compulsory/secondary school/university); work status (employed full time/part time, early retirement/disability pension, full time/part time, retired, unemployed, others); Immigrant status was assessed by a question of country of birth. Not born in Sweden was in present study defined as immigrant; physical activity in leisure time (response alternatives; (1) sedentary in leisure time, (2) moderate exercise in leisure time (walking, riding bicycle, light gardening for a minimum of 4 hours), (3) regular exercise and training (strenuous activity for a minimum of 3 hours/week), (4) intense training or competitive sport); physician confirmed diabetes (yes/no); physician confirmed hypertension (yes/no); current smoker (yes/no); ex-smoker (yes/no); alcohol consumption (response alternatives including; frequency and amount each week/month/day). Weight and height were self-reported by UCP patients but measured in reference group at the screening examination.

\section{Statistical analyses}

The analyses were carried out using the Statistical Analysis System (SAS) 8.2 (SAS Institute Inc., Cary, NC). Differences between the UCP patients and the referents in terms of demographic and psychosocial factors were tested by the chi-square test for discrete variables and by Student's t-test for continuous variables. Odds ratios were calculated for selected background characteristics and psychosocial variables simultaneously controlling for age, smoking, hypertension and diabetes. Multivariate logistic stepwise regression models were used. In step 1 , all variables were included if $\mathrm{p}<0.10$ in the univariate analysis. In step 2 , variables were included if $\mathrm{p}<0.10$ in step 1 . A twosided $\mathrm{p} \leq 0.05$ was considered significant.

\section{Results}

Demographics and background characteristics in the UCP patients and the reference group are shown in Table 2. The mean age of the UCP men was significantly lower (45.7 years) compared with the male referents (48.7 years). Twenty five per cent of the UCP women had attended university, compared with $45 \%$ of the referents. Differences in education for men were less pronounced. The UCP patients, particularly the UCP women, had more hypertension compared with the female referents $(\mathrm{p}<0.0001)$.

Table I: Measurement scales used in the study and their reliability.

\begin{tabular}{|c|c|c|c|c|c|}
\hline Scale & Assessment & Items & Scale score & Reliability & References \\
\hline Interview Schedule & Social integration & 6 & $0-30$ & Test-retest reliability 0.75 & Henderson et al. 1980 \\
\hline for Social Interaction & Social attachment & 8 & $0-16$ & Test-retest reliability 0.76 & Undén et al. 1989 \\
\hline Zung Self-Rating & Symptoms of depression & 20 & $20-80$ & Chronbach's alpha 0.92 & Zung 1965 \\
\hline \multicolumn{6}{|l|}{ Depression Scale } \\
\hline Trait-Anxiety & Trait anxiety & 20 & $20-80$ & Chronbach's alpha 0.83 to 0.92 & Spielberg 1968 \\
\hline \multicolumn{6}{|l|}{ Inventory } \\
\hline SF 36 & Health-related quality of life & 36 & $0-100$ & Chronbach's alpha 0.79 to 0.93 & Sullivan, Karlsson 1994 \\
\hline
\end{tabular}


Table 2: Demographic and background characteristics in UCP patients ( 127 men, 104 women) and referents (490 men, 579 women).

\begin{tabular}{|c|c|c|c|c|c|}
\hline & \multicolumn{2}{|c|}{ UCP } & \multicolumn{2}{|c|}{ Referents } & \multirow[b]{2}{*}{$\mathrm{P}$-value } \\
\hline & $\%$ & $(n)$ & $\%$ & $(n)$ & \\
\hline \multicolumn{6}{|l|}{ MEN } \\
\hline Age, years, mean (SD) & 45.7 & (II.I) & 48.7 & $(12.3)$ & 0.01 \\
\hline Single & 24 & $(3 I)$ & 28 & $(135)$ & 0.45 \\
\hline University education & 28 & (35) & 38 & $(184)$ & 0.04 \\
\hline Employed & 71 & $(90)$ & 72 & $(348)$ & 0.87 \\
\hline Current smoker & 16 & (20) & 17 & $(84)$ & 0.70 \\
\hline Diabetes $^{\mathrm{a}}$ & 4 & (5) & 5 & (24) & 0.68 \\
\hline Hypertension ${ }^{\mathrm{a}}$ & 20 & $(25)$ & 14 & $(67)$ & 0.07 \\
\hline Body mass index, mean (SD) & 27.4 & (3.5) & 26.5 & (3.6) & 0.01 \\
\hline Alcohol consumption g/week, mean (SD) & 32.7 & $(25.6)$ & 48.8 & $(34.5)$ & $<.0001$ \\
\hline \multicolumn{6}{|l|}{ WOMEN } \\
\hline Age, years, mean (SD) & 47.7 & $(11.9)$ & 47.1 & $(12.2)$ & 0.68 \\
\hline Single & 30 & $(31)$ & 35 & $(199)$ & 0.33 \\
\hline University education & 25 & (26) & 45 & $(259)$ & 0.0001 \\
\hline Employed & 60 & $(62)$ & 69 & $(398)$ & 0.05 \\
\hline Current smoker & 34 & (35) & 22 & $(125)$ & 0.01 \\
\hline Diabetes $^{\mathrm{a}}$ & 6 & (6) & I & (6) & 0.001 \\
\hline Hypertension ${ }^{\mathrm{a}}$ & 30 & (30) & 12 & $(72)$ & $<.0001$ \\
\hline Body mass index, mean (SD) & 26.7 & $(5.9)$ & 25.1 & (4.4) & 0.01 \\
\hline Alcohol consumption g/week, mean (SD) & 18.0 & $(25.7)$ & 28.2 & $(20.0)$ & 0.0002 \\
\hline
\end{tabular}

a Physician confirmed

BMI was significantly higher in both UCP men and women than in the reference group. Current smoking was more common among UCP women than among their referents, whereas there were no differences in reported smoking among the men. In contrast, reported alcohol consumption/week was significantly lower in the UCP patients, among both men and women.

The percentage of immigrants was significantly higher among the UCP patients and these patients were also significantly more sedentary during their leisure time, compared with the reference group (Table 3 ). Twice as many men and three times as many women were immigrants among the UCP patients in comparison with the reference group. After adjustment for age, smoking, hypertension and diabetes, a significantly increased risk persisted (OR $2.6(1.7-4.2), 3.7(2.2-6.3))$, in men and women respectively. A sedentary lifestyle was also significantly associated with UCP after adjustment for age, smoking, hypertension and diabetes (OR 2.9 (1.7-4.9) and 2.0 (1.1-3.7) for men and women respectively).

UCP patients reported significantly more stress at work, symptoms of depression and trait-anxiety than the reference group (Table 3). After adjusting for age, smoking, hypertension and diabetes, these factors were still significantly more common among patients with UCP for both men and women; perceived stress at work OR 3.5 (2.1-
$6.0)$ and 2.0 (1.1-3.4), for men and women respectively; symptoms of depression OR $2.3(1.4-3.6)$ and 2.5 (1.63.9); and trait-anxiety OR $2.2(1.4-3.5)$ and $1.8(1.1-2.8)$. Mental strain in marriage/cohabitation and low social integration only emerged as significant risk factors among women, after adjustment for age, smoking, hypertension and diabetes OR $2.3(1.0-5.3)$ and OR 1.8 (1.1-2.9) respectively.

Table 4 presents a multivariate model in which significant background variables and psychosocial factors were taken into account. Being an immigrant emerged as an independent risk factor in both men (OR 2.05 (1.15-3.66)) and women (OR 2.76 (1.56-4.86)), while alcohol consumption also retained its independent significance (OR 0.98 (0.97-0.99), OR 0.97 (0.95-0.99) for men and women respectively. After adjustment, stress at work was associated with an almost fourfold increase in risk among men (OR 3.94 (2.26-6.85)), whereas there was no independent impact for women. In contrast, university education was an independent protective factor among women, with an OR of $0.47(0.28-0.79)$. A sedentary lifestyle was associated with a twofold risk (OR 2.00 (1.06-3.79)), but only in men, whereas depression only emerged as an independent risk factor in women (OR 2.09 (1.30-3.38)). Trait-anxiety and low social interaction were not independently associated with risk in either men or women. 
Table 3: Comparison between 23I UCP patients ( 127 men, 104 women) and 1069 referents (490 men, 579 women).

\begin{tabular}{|c|c|c|c|c|c|c|c|c|}
\hline & \multicolumn{2}{|c|}{ UCP } & \multicolumn{2}{|c|}{ Referents } & \multirow[b]{2}{*}{ OR } & \multirow[b]{2}{*}{$(95 \% \mathrm{Cl})$} & \multicolumn{2}{|c|}{ Adjustedt } \\
\hline & $\%$ & (n) & $\%$ & (n) & & & OR & $(95 \% \mathrm{Cl})$ \\
\hline \multicolumn{9}{|l|}{ MEN } \\
\hline Immigrant ${ }^{\mathrm{a}}$ & 33 & $(42)$ & 16 & (78) & 2.6 & $(1.7-4.0)$ & 2.6 & $(1.7-4.2)$ \\
\hline Sedentary in leisure time & 25 & (3I) & 11 & (54) & 2.6 & $(1.6-4.3)$ & 2.9 & $(1.7-4.9)$ \\
\hline Perceived stress at work ${ }^{b}$ & 35 & (36) & 12 & (55) & 3.9 & $(2.4-6.4)$ & 3.5 & $(2.1-6.0)$ \\
\hline Mental strain in the marriage/cohabitation, score $\geq 7 c$ & 7 & (9) & 4 & (19) & 1.9 & $(0.8-4.3)$ & 2.0 & $(0.9-4.5)$ \\
\hline Depression, score $\geq 39 d$ & 35 & $(43)$ & 18 & (87) & 2.4 & $(1.6-3.8)$ & 2.3 & $(1.4-3.6)$ \\
\hline Trait-anxiety, score $\geq 43^{d}$ & 36 & (44) & 19 & (89) & 2.4 & $(1.6-3.7)$ & 2.2 & $(1.4-3.5)$ \\
\hline Low social integration, score $\leq 9 \mathrm{e}$ & 21 & $(26)$ & 20 & (97) & I.I & $(0.7-1.8)$ & 1.2 & $(0.7-2.0)$ \\
\hline Low social attachment, score $\leq \mathrm{I}^{\mathrm{f}}$ & 16 & (20) & 23 & (109) & 0.6 & $(0.4-1.1)$ & 0.7 & $(0.4-1.3)$ \\
\hline \multicolumn{9}{|l|}{ WOMEN } \\
\hline Immigrant ${ }^{\mathrm{a}}$ & 31 & $(32)$ & 11 & (63) & 3.7 & $(2.3-6.1)$ & 3.7 & $(2.2-6.3)$ \\
\hline Sedentary in leisure time & 20 & $(20)$ & 9 & (52) & 2.5 & $(1.4-4.4)$ & 2.0 & $(1.1-3.7)$ \\
\hline Perceived stress at work ${ }^{b}$ & 32 & $(25)$ & 18 & (96) & 2.1 & $(1.3-3.6)$ & 2.0 & $(1.1-3.4)$ \\
\hline Mental strain in the marriage/cohabitation, score $\geq 7 c$ & 10 & (9) & 5 & (26) & 2.2 & $(1.0-4.9)$ & 2.3 & $(1.0-5.3)$ \\
\hline Depression, score $\geq 39 \mathrm{~d}$ & 50 & $(50)$ & 28 & (159) & 2.6 & $(1.7-4.1)$ & 2.5 & $(1.6-3.9)$ \\
\hline Trait-anxiety, score $\geq 43^{d}$ & 47 & (47) & 30 & (169) & 2.1 & $(1.4-3.3)$ & 1.8 & $(1.1-2.8)$ \\
\hline Low social integration, score $\leq 9 \mathrm{e}$ & 32 & $(31)$ & 20 & $(112)$ & 2.0 & $(1.2-3.1)$ & 1.8 & $(1.1-2.9)$ \\
\hline Low social attachment, score $\leq \mathrm{II}^{\mathrm{f}}$ & II & (II) & 16 & $(90)$ & 0.6 & $(0.3-1.3)$ & 0.5 & $(0.3-1.1)$ \\
\hline
\end{tabular}

$\dagger$ Adjusted for age, smoking, hypertension, and diabetes; a Not born in Sweden; ${ }^{b}$ Constant during the last year or the last five years; ${ }^{\mathrm{c}}$ Two items, total score 2-10; d Highest quintile in the total referent group, scale score 20-80; e Lowest quintile in the total referent group, scale score 0-30; ${ }^{f}$ Lowest quintile in the total referent group, scale score 0-16;

Raw scores of assessed HRQOL in the SF 36, demonstrated that the UCP patients, both men and women, perceived their HRQOL lower than their referents (Table 5). Odds Ratio calculated on all the subscales showed that patients with UCP were two to five times more likely to have low scores of HRQOL (Table 6).

\section{Discussion}

In this study, in which UCP patients were compared with a reference group from the general population, we found that the patients differed from the reference group in several respects. After adjusting for differences in age, smoking, hypertension and diabetes, UCP patients were more likely than the referents to be immigrants, perceived more stress at work and had more symptoms of depression and trait-anxiety.

Twice as many UCP patients, compared with reference group, were immigrants, despite the fact that one in ten of the potentially eligible UCP patients was excluded due to language difficulties. One reason for the large number of immigrants admitted to the ED might be that immigrants are not entirely familiar with the Swedish health-care organisation. Instead of seeking care for UCP in primary health care, they sought care at the ED. Also the combination of chest pain, higher levels of risk factors and symptoms of depression and anxiety in the UCP patients in general, might be a reason to contact the ED for investigation.

In agreement with the present study, it has previously been found that immigrants were likely to have more cardiovascular risk factors than Swedish-born individuals, but the incidence of MI was equal in Swedish-born individuals and immigrants. The decreasing trend in coronary heart disease (CHD) in Sweden [17] is unlikely to be explained by the increasing number of immigrants.

The present study revealed differences in educational level between the patients, particularly the women, and the reference group. Twice as many female referents compared with cases had a university education, which is an important finding, as previous studies have indicated that education may be a protective factor for cardiovascular disease $[18,19]$.

The overall prevalence of smoking among men, both cases and referents, as well as in female reference group, was low, reflecting the overall low prevalence of smoking in Sweden, whereas one in three women with UCP was an active smoker. However, after taking differences in education and other factors into account, smoking did not differ between female cases and referents. 
Table 4: Comparison between UCP patients and referents in multivariate analyses. In step I, all variables are included if $p<0.10$ in univariate analysis. In step 2 , variables are included if $p<0.10$ in step $I$.

\begin{tabular}{|c|c|c|c|c|c|c|}
\hline \multirow[t]{2}{*}{ MEN } & \multicolumn{2}{|c|}{ Step I } & \multirow[b]{2}{*}{$\mathrm{P}$-value } & \multicolumn{2}{|c|}{ Step 2} & \multirow[b]{2}{*}{ p-value } \\
\hline & OR & $(95 \% \mathrm{Cl})$ & & OR & $(95 \% \mathrm{Cl})$ & \\
\hline Age, per year & 0.95 & $(0.93-0.98)$ & $<0.0001$ & 0.96 & $(0.94-0.98)$ & $<0.0001$ \\
\hline University education, yes/no & 0.69 & $(0.40-1.18)$ & 0.18 & & & \\
\hline Immigrant ${ }^{a}$, yes/no & 1.76 & $(0.95-3.26)$ & 0.07 & 2.05 & $(1.15-3.66)$ & 0.02 \\
\hline Hypertension ${ }^{b}$, yes/no & 1.32 & $(0.62-2.80)$ & 0.46 & & & \\
\hline Body mass index & 1.04 & $(0.97-1.11)$ & 0.32 & & & \\
\hline Sedentary at leisure time, yes/no & 1.81 & $(0.93-3.51)$ & 0.08 & 2.00 & $(1.06-3.79)$ & 0.03 \\
\hline Alcohol consumption, g/week & 0.98 & $(0.97-0.99)$ & $<0.0001$ & 0.98 & $(0.97-0.99)$ & $<0.0001$ \\
\hline Perceived stress at work ${ }^{c}$ & 2.69 & $(1.47-4.95)$ & 0.001 & 3.94 & $(2.26-6.85)$ & $<0.0001$ \\
\hline Depression, score $\geq 39 \mathrm{~d}$ & 1.52 & $(0.7 I-3.28)$ & 0.28 & & & \\
\hline Trait-anxiety, score $\geq 43 \mathrm{e}$ & 1.17 & $(0.53-2.56)$ & 0.70 & & & \\
\hline Low social attachment, score $\leq \mathrm{II}^{\mathrm{f}}$ & 0.50 & $(0.25-1.00)$ & 0.05 & 0.54 & $(0.28-1.03)$ & 0.06 \\
\hline \multirow[t]{2}{*}{ WOMEN } & \multicolumn{2}{|c|}{ Step I } & & \multicolumn{2}{|c|}{ Step 2} & \\
\hline & OR & $(95 \% \mathrm{Cl})$ & $\mathrm{P}$-value & OR & $(95 \% \mathrm{Cl})$ & $\mathrm{p}$-value \\
\hline University education, yes/no & 0.45 & $(0.24-0.84)$ & 0.01 & 0.47 & $(0.28-0.79)$ & 0.004 \\
\hline Employed, yes/no & 2.06 & $(0.97-4.38)$ & 0.06 & 1.36 & $(0.8 \mathrm{I}-2.30)$ & 0.24 \\
\hline Immigranta ${ }^{a}$, yes/no & 2.56 & $(1.25-5.24)$ & 0.01 & 2.76 & $(1.56-4.86)$ & 0.0005 \\
\hline Current smoker, yes/no & 1.54 & $(0.82-2.90)$ & 0.18 & & & \\
\hline Diabetes ${ }^{b}$, yes/no & 2.43 & $(0.46-12.79)$ & 0.29 & & & \\
\hline Hypertensionb, yes/no & 2.12 & $(1.01-4.44)$ & 0.05 & 2.30 & $(1.30-4.05)$ & 0.004 \\
\hline Body mass index & 1.02 & $(0.96-1.09)$ & 0.47 & & & \\
\hline Sedentary at leisure time, yes/no & 1.71 & $(0.73-4.02)$ & 0.22 & & & \\
\hline Alcohol consumption, g/week & 0.98 & $(0.96-1.00)$ & 0.02 & 0.97 & $(0.95-0.99)$ & 0.002 \\
\hline Perceived stress at work ${ }^{c}$ & 1.62 & $(0.83-3.15)$ & 0.16 & & & \\
\hline Mental strain in the marriage/cohabitation, score $\geq 7 \mathrm{~g}$ & 0.94 & $(0.31-2.88)$ & 0.92 & & & \\
\hline Depression, score $\geq 39 \mathrm{~d}$ & 2.07 & $(0.97-4.44)$ & 0.06 & 2.09 & $(1.30-3.38)$ & 0.002 \\
\hline Trait-anxiety, score $\geq 43^{\mathrm{e}}$ & 0.93 & $(0.43-2.02)$ & 0.86 & & & \\
\hline Low social integration, score $\leq 9 \mathrm{~h}$ & 0.81 & $(0.40-1.62)$ & 0.55 & & & \\
\hline
\end{tabular}

a Not born in Sweden; b Physician confirmed; c Constant during the last year or the last five years; ${ }^{\mathrm{C}}$ Zung depression scale, score 20-80; e Traitanxiety inventory, score 20-80; f ISSI-subscale, score 0-16; g Two items, total score 2-10; h ISSI-subscale, score 0-30;

Furthermore, UCP patients, both men and women, reported lower alcohol consumption, an unexpected finding, because UCP is associated with anxiety, depression and impaired mental well-being, which, in turn, is a risk for high alcohol consumption [20]. Previous studies investigating the connection between cardiovascular diseases and alcohol consumption in men and women indicated that moderate alcohol consumption might be a protective factor [20-22]. Why this should extend to chest pain patients is unclear.

From 1985 to 2002, the prevalence of overweight and obesity in the general population increased, particularly in men, while leisure activity increased in women [10]. Both inactivity and obesity are well-known risk factors for IHD [23]. Our results suggest that obese and sedentary individuals may also be at risk of UCP. An alternative explanation for the higher levels of traditional risk factors might be that some patients, despite a lack of objective signs still have had undetected IHD. A large percentage of unrecognised myocardial infarction - $19 \%$ - was found in a sample of Swedish men and women aged 70 [24].

UCP patients in the present study reported perceived stress at work (constant during the last year or the last five years) to a higher extent than the reference group. This has previously been found in a qualitative study of UCP patients [8]. The results are also in agreement with a study by Jerlock et al. [25] investigating stress at work among UCP patients where $18 \%$ of patients reported permanent stress. Future research should address the question of whether patients suffering from UCP have more stressful work environments or a poorer ability to cope with stress in general. 
Table 5: Health-related quality of life (HRQOL) in patients with unexplained chest pain (UCP) and referents.

\begin{tabular}{|c|c|c|c|c|c|c|}
\hline \multirow[b]{2}{*}{ Subscales SF $36^{a}$} & \multicolumn{3}{|c|}{ MEN } & \multicolumn{3}{|c|}{ WOMEN } \\
\hline & $U C P n=127$ & Referents $n=490$ & $\mathrm{p}$-value & $\mathrm{UCP} n=104$ & Referents $n=579$ & $\mathrm{P}$-value \\
\hline Physical functioning, mean & 84,7 & 90,9 & 0.001 & 73,0 & 88,1 & $<.0001$ \\
\hline Role physical, mean & 75,2 & 86,6 & $<.0001$ & 68,8 & 83,1 & $<.0001$ \\
\hline Vitality, mean & 55,2 & 78,5 & $<.0001$ & 53,6 & 71,5 & $<.0001$ \\
\hline Bodily pain, mean & 66,9 & 73,1 & $<.0001$ & 60,0 & 72,4 & $<.0001$ \\
\hline General health, mean & 51,7 & 65,8 & 0.006 & 44,5 & 58,8 & $<.0001$ \\
\hline Social functioning, mean & 73,4 & 84,3 & $<.0001$ & 66,5 & 79,6 & $<.0001$ \\
\hline Role emotional, mean & 78,8 & 87,1 & 0.001 & 72,7 & 84,9 & $<.0001$ \\
\hline Mental health, mean & 68,5 & 77,9 & $<.0001$ & 59,9 & 73,3 & $<.0001$ \\
\hline
\end{tabular}

a Scale score $0-100$

The present study indicates that almost twice as many UCP patients reported higher scores for symptoms of depression and trait-anxiety. The associations between chronic pain and depressive symptoms in an elderly population have previously been studied, with significant associations between pain experience and depressive symptoms, particularly in men. In that study, women consumed more antidepressants and reported a higher level of daily pain [26]. When comparing patients with ischemic heart disease with patients with non-specific chest pain, Tew [27] found that the latter appeared to be more anxious and worried more about their symptoms. Another study evaluating non-cardiac chest pain found that $57 \%$ of the included patients suffered from depression and anxiety and suggested that possible psychiatric disorders could be identified since impaired quality of life and pathological coping strategies were found in these patients [28]. Likewise, in the present study, the UCP patients reported a lower HRQOL, in agreement with other earlier studies, indicating that patients with chest pain have impaired quality of life [29-32]. The effect of childhood adversity, mental distress and lack of social support might also have an effect on perceived HRQOL in patients with non-cardiac chest pain, demonstrated in a study of Biggs et al [33].

Esler and Bock [34] claim that a new approach to treating patients suffering from non-cardiac chest pain is needed and recommend a brief intervention delivered at the $\mathrm{ED}$, based on the biopsychosocial model, in order to reduce health-care utilisation, reduce psychological distress and improve health-related quality of life. Atienza et al stress that using a specific questionnaire; a reliable and sensitive tool, when assessing quality of life in chest pain patients,

Table 6: Health-related quality of life (HRQOL) in patients with unexplained chest pain (UCP) and referents.

\begin{tabular}{|c|c|c|c|c|c|c|c|c|c|c|c|c|c|c|}
\hline \multirow[b]{3}{*}{ Subscales SF 36} & \multicolumn{7}{|c|}{ MEN } & \multicolumn{7}{|c|}{ WOMEN } \\
\hline & \multicolumn{2}{|c|}{$\mathrm{UCP} n=127$} & \multicolumn{2}{|c|}{ Referents $n=490$} & \multirow[b]{2}{*}{$\mathrm{P}$-value } & \multirow[b]{2}{*}{ OR } & \multirow[b]{2}{*}{$95 \% \mathrm{Cl}$} & \multicolumn{2}{|c|}{$\mathrm{UCP} n=104$} & \multicolumn{2}{|c|}{ Referents $n=579$} & \multirow[b]{2}{*}{$\mathrm{P}$-value } & \multirow[b]{2}{*}{ OR } & \multirow[b]{2}{*}{$(95 \% \mathrm{Cl})$} \\
\hline & $\%$ & (n) & $\%$ & $(n)$ & & & & $\%$ & (n) & $\%$ & (n) & & & \\
\hline $\begin{array}{l}\text { Physical functioning, } \\
\text { index score } \leq 80^{\mathrm{a}}\end{array}$ & 31 & (39) & 16 & $(77)$ & $<.0001$ & 2.5 & $(1.6-3.9)$ & 49 & $(47)$ & 24 & $(137)$ & $<.0001$ & 3.1 & $(2.0-4.8)$ \\
\hline $\begin{array}{l}\text { Role physical, index } \\
\text { score } \leq 69 \mathrm{a}\end{array}$ & 38 & $(46)$ & 18 & $(85)$ & $<.0001$ & 2.9 & $(1.9-4.5)$ & 51 & $(49)$ & 23 & $(133)$ & $<.0001$ & 3.5 & $(2.2-5.4)$ \\
\hline $\begin{array}{l}\text { Vitality, index score } \leq \\
38^{\mathrm{a}}\end{array}$ & 32 & (39) & 14 & $(67)$ & $<.0001$ & 2.9 & $(1.8-4.6)$ & 42 & $(4 I)$ & 22 & $(125)$ & $<.0001$ & 2.6 & $(1.7-4.1)$ \\
\hline $\begin{array}{l}\text { Bodily pain, index } \\
\text { score } \leq 50^{\mathrm{a}}\end{array}$ & 41 & $(50)$ & 12 & $(58)$ & $<.0001$ & 5.1 & $(3.3-8.1)$ & 50 & $(48)$ & 23 & $(132)$ & $<.0001$ & 3.3 & $(2.1-5.2)$ \\
\hline $\begin{array}{l}\text { General health, index } \\
\text { score } \leq 55^{\mathrm{a}}\end{array}$ & 32 & (39) & 20 & $(96)$ & 0.005 & 1.9 & $(1.2-2.9)$ & 40 & (38) & 21 & $(121)$ & $<.0001$ & 2.5 & $(1.6-3.9)$ \\
\hline $\begin{array}{l}\text { Social functioning, } \\
\text { index score } \leq 50^{\mathrm{a}}\end{array}$ & 28 & $(35)$ & 14 & $(67)$ & 0.0001 & 2.5 & $(1.6-4.0)$ & 39 & (38) & 20 & $(117)$ & $<.0001$ & 2.5 & $(1.6-3.9)$ \\
\hline $\begin{array}{l}\text { Role emotional, index } \\
\text { score } \leq 67^{\mathrm{a}}\end{array}$ & 30 & $(35)$ & 17 & $(80)$ & 0.001 & 2.2 & $(1.4-3.5)$ & 39 & (37) & 20 & $(115)$ & $<.0001$ & 2.6 & $(1.6-4.1)$ \\
\hline $\begin{array}{l}\text { Mental health, index } \\
\text { score } \leq 60^{\mathrm{a}}\end{array}$ & 38 & $(47)$ & 18 & $(87)$ & $<.0001$ & 2.8 & $(1.8-4.4)$ & 53 & (52) & 24 & $(140)$ & $<.0001$ & 3.5 & $(2.3-5.5)$ \\
\hline
\end{tabular}

a Lowest quintile in the total referent group, scale score $0-100$ 
is most desirable [35]. Furthermore, guidelines for the treatment of chest pain patients at the ED could potentially improve the clinical decision-making and reduce the re-admission of patients with cardiac or possible cardiac chest pain [36].

Patients with medically unexplained symptoms include a great number of all patients seeking care. Several of theses patients have culturally founded models explaining their somatic symptoms, and research has demonstrated that e.g. pain experience can be expressed in various ways in different cultures $[37,38]$. This has to be considered in the care of the immigrants among the UCP patients. In accordance with findings in our study, Kirmayer \& Yong (1998) found that patients with e.g. panic disorder or symptoms of depression and anxiety also present somatic symptoms [39].

In present study there were few gender differences between UCP patients and referents: UCP women had less education and more symptoms of depression, UCP men perceived more often stress at work and reported more sedentary in leisure time. These gender differences might be explained by the number of immigrants among UCP patients. According to Bendelow, gender differences in perception of pain can be affected of different factors like sex roles and cultural socialisation [40].

There are several limitations to this study. One inherent feature of a case-reference study is the problem of determining what is cause and what is effect, e.g. are the UCP patients less active because they have chest pain or the reverse? Secondly, the data relating to the UCP patients were relatively small, only collected during office hours Monday through Friday. Only patients who understood Swedish were included, because of the need to understand Swedish when filling in the questionnaire. This may have influenced our results, but we believe it is unlikely that patients with UCP who were immigrants or who sought care during out-of-office hours had lower levels of stress and other psychosocial factors than the UCP patients who were included. Thirdly, the UCP female sample was relatively small, limiting the statistical power of our analyses. The results showed that the male UCP patients were younger than their referents. A further limitation may be that persons $<25$ years old were not included due to the reference group (25-69 years). In addition, self-reported data for height and weight were used for the UCP patients but not for the reference group. It is therefore likely that the differences in BMI and obesity are even larger, since the under-reporting of weight and height is well documented $[41,42]$. Finally, a proportion of the referents, or $26 \%$, did not complete all the questionnaires. The noncompleters were somewhat older, with less education, which could have exaggerated differences between chest pain cases and the reference group.

\section{Conclusion}

In this study, we found that UCP patients were likely to be immigrants, perceived more stress at work and had more symptoms of depression and trait-anxiety, compared with the participants in the reference group. After adjustment for differences in age, smoking, hypertension and diabetes, these factors were still significantly more common among patients with UCP. The results of the present study indicate that matters relating to work situation, psychosocial factors and to be an immigrant, may be of importance in the patient's decision to seek care for their chest pain. Further research should be directed not only at more efficient ways of identifying organic causes of chest pain but also to a more systematic evaluation of their symptoms, or the potential effects of lifestyle counselling in this large patient population.

\section{Competing interests}

The authors declare that they have no competing interests.

\section{Authors' contributions}

$\mathrm{AJF}, \mathrm{AR}$ and $\mathrm{CW}$ contributed to the design. AJF collected the data in cases. LL was responsible for the collection of psychosocial data in the reference sample. AJF, KIK and $\mathrm{CW}$ carried out the data analysis and interpreted the data. AJF wrote the manuscript. $\mathrm{KIK}, \mathrm{AR}, \mathrm{LL}, \mathrm{KM}$ and $\mathrm{CW}$ revised the manuscript for important intellectual content. All the authors have read and approved the final manuscript.

\section{Acknowledgements}

The study was supported by grants from the Swedish Heart and Lung Foundation (no. 20060954) and the Swedish Council for Working Life and Social Research (FAS 2006-I 506, 2005-0094, 2005-0478).

\section{References}

I. Eslick GD, Coulshed DS, Talley NJ: Review article: the burden of illness of non-cardiac chest pain. Aliment Pharmacol Ther 2002, 16:1217-1223.

2. Murphy NF, Maclntyre K, Capewell S, Stewart S, Pell J, Chalmers J, Redpath A, Frame S, Boyd J, McMurray J]: Hospital discharge rates for suspected acute coronary syndromes between 1990 and 2000: population based analysis. BMJ 2004, 328:|4|3-|4|4.

3. Eslick GD, Talley NJ: Non-cardiac chest pain: predictors of health care seeking, the types of health care professional consulted, work absenteeism and interruption of daily activities. Aliment Pharmacol Ther 2004, 20:909-915.

4. Galmiche JP, Clouse RE, Balint A, Cook IJ, Kahrilas PJ, Paterson WG, Smount AJMP: Functional Esophageal Disorders. Gastroenterology 2006, I 30: I 459-1465.

5. Fox M, Forgacs I: Unexplained (non-cardiac) chest pain. Clin Med 2006, 6:445-449.

6. Keogh E, Hamid R, Hamid S, Ellery D: Investigating the effect of anxiety sensitivity, gender and negative interpretative bias on the perception of chest pain. Pain 2004, I I I:209-2 I7.

7. Eslick GD, Coulshed DS, Talley NJ: Diagnosis and treatment of noncardiac chest pain. Nat Clin Pract Gastroenterol Hepatol 2005, 2:463-472. 
8. Janson Fagring A, Gaston-Johansson F, Danielson E: Description of unexplained chest pain and its influence on daily life in men and women. Eur J Cardiovasc Nurs 2005, 4:337-344.

9. Jerlock M, Gaston-Johansson F, Danielson E: Living with unexplained chest pain. J Clin Nurs 2005, 14:956-964.

10. Berg C, Rosengren A, Aires N, Lappas G, Toren K, Thelle D, Lissner L: Trends in overweight and obesity from 1985 to 2002 in Goteborg, West Sweden. Int J Obes 2005, 29:916-924.

II. Henderson S, Duncan-Jones P, Byrne DG, Scott R: Measuring social relationships. The Interview Schedule for Social Interaction. Psychol Med 1980, 10:723-734

12. Spielberg CD, Gorsuch RL, Lushene RE: The State-Trait Anxiety Inventory (STAl Manual) Talhasse, Florida: Florida State University; 1968.

13. Sullivan M, Karlsson J: SF 36, Swedish manual and interpretation guide Gothenburg University and Sahlgrenska Hospital; 1994.

14. Undén A-L, Orth-Gomér K: Development of a Social Support Instrument for use in population surveys. Soc Sci Med 1989, 29:1387-1392.

15. Zung WW: A Self-Rating Depression Scale. Arch Gen Psychiatry 1965, I 2:63-70.

16. Welin C: Psychosocial Factors in Myocardial Infarction Patients-A Case-Control Study. In PhD thesis Göteborg University; Sweden; 1995.

17. Dotevall A, Rosengren A, Lappas G, Wilhelmsen L: Does immigration contribute to decreasing CHD incidence? Coronary risk factors among immigrants in Goteborg, Sweden. J Intern Med 2000, 247:33I-339.

18. Kilander L, Berglund L, Boberg M, Vessby B, Lithell H: Education, lifestyle factors and mortality from cardiovascular disease and cancer. A 25-year follow-up of Swedish 50-year-old men. Int J Epidemiol 2001, 30: I II9-1 I26.

19. Strand BH, Tverdal A: Can cardiovascular risk factors and lifestyle explain the educational inequalities in mortality from ischaemic heart disease and from other heart diseases? 26 year follow up of 50,000 Norwegian men and women. J Epidemiol community health 2004, 58:705-709.

20. Bostrom G: : habits of life and health. Scand J PublicHealth 2006 , 67:199-228.

21. Janszky I, Mukamal KJ, Orth-Gomer K, Romelsjo A, Schenck-Gustafsson K, Svane B, Kirkeeide RL, Mittleman MA: Alcohol consumption and coronary atherosclerosis progression - the Stockholm Female Coronary Risk Angiographic Study. Atherosclerosis 2004, I 76:31।-319.

22. Marques-Vidal P, Montaye M, Arveiler D, Evans A, Bingham A, Ruidavets JB, Amouyel $P$, Haas B, Yarnell J, Ducimetiere $P$, Ferriéres ]: Alcohol consumption and cardiovascular disease: differential effects in France and Northern Ireland. The PRIME study. Eur I Cardiovasc Prev Rehabil 2004, I I:336-343.

23. Fransson E, de Faire U, Ahlbom A, Reuterwall C, Hallqvist J, Alfredsson $L$ : The effect of leisure-time physical activity on the risk of acute myocardial infarction depending on body mass index: a population-based case-control study. BMC Public Health 2006, 6:296.

24. Barbier CE, Bjerner T, Johansson L, Lind L, Ahlstrom H: Myocardial scars more frequent than expected: magnetic resonance imaging detects potential risk group. J AM Coll Cardiol 2006 , 48:765-77।

25. Jerlock M, Gaston-Johansson F, Kjellgren KI, Welin C: Coping strategies, stress, physical activity and sleep in patients with unexplained chest pain. BMC Nurs 2006, 5:7.

26. Bergh I, Steen G, Waern M, Johansson B, Oden A, Sjostrom B, Steen $B$ : Pain and its relation to cognitive function and depressive symptoms: a Swedish population study of 70-year-old men and women. J Pain Symptom Manage 2003, 26:903-912

27. Tew R, Guthrie EA, Creed FH, Cotter L, Kisely S, Tomenson B: A long-term follow-up study of patients with ischaemic heart disease versus patients with nonspecific chest pain. I Psychosom Res 1995, 39:977-985

28. Husser D, Bollmann A, Kuhne C, Molling J, Klein HU: Evaluation of noncardiac chest pain: diagnostic approach, coping strategies and quality of life. Eur J Pain 2006, 10:5I-55.

29. Goodacre S, Mason S, Arnold J, Angelini K: Psychologic morbidity and health-related quality of life of patients assessed in a chest pain observation unit. Ann Emerg Med 200I, 38:369-376.

30. Wong W-M, Lai KC, Lau CP, Hu WHC, Chen WH, Wong BCY, Hu WM, Wong YH, Xia HHX, Lam SK: Upper gastrointestinal eval- uation of Chinese patients with non-cardiac chest pain. Aliment Pharmacol Ther 2002, 16:465-471.

3I. Eslick GD, Jones MP, Talley NJ: Non-cardiac chest pain: prevalence, risk factors, impact and consulting-a population-based study. Aliment Pharmacol Ther 2003, 17: I I I5-I I24.

32. Fagring AJ, Gaston-Johansson F, Kjellgren KI, Welin C: Unexplained chest pain in relation to psychosocial factors and healthrelated quality of life in men and women. Eur J Cardiovasc Nurs 2007, 6:329-336.

33. Biggs AM, Aziz Q, Tomenson B, Creed F: Effect of childhood adversity on health related quality of life in patients with upper abdominal or chest pain. Oesophagus 2004, 53:180-186.

34. Esler JL, Bock BC: Psychological treatments for noncardiac chest pain: recommendations for a new approach. J Psychosom Res 2004, 56:263-269.

35. Atienza F, Velasco JA, Brown S, Ridocci F, Kaski JC: Assessment of quality of life in patients with chest pain and normal coronary arteriogram (syndrome $X$ ) using a specific questionnaire. Clin Cardiol 1999, 22:283-290.

36. Boufous S, Kelleher PW, Pain CH, Dann LM, leraci S, Jalaludin BB, Gray AL, Harris SE, Juergens CP: Impact of a chest-pain guideline on clinical decision-making. Med J Aust 2003, 178:375-380.

37. Kirmayer LJ, Groleau D, Looper KJ, Dao MD: Explaining medically unexplained symptoms. Can J Psychiatry 2004, 49:663-672

38. Eisenberg L, Kleinman A: The relevance of social science for medicine Dordrecht: Reidel; |98I.

39. Kirmayer LJ, Yong A: Culture and somatization: clinical, epidemiological, and ethnographic perspectives. Psychosom Med 1998, 60:420-430.

40. Bendelow G: Pain and gender Essex: Pearson Education Ltd; 2000.

4I. Danubio ME, Miranda G, Vinciguerra MG, Vecchi E, Rufo F: Comparison of self-reported and measured height and weight: Implications for obesity research among young adults. Econ Hum Biol 2008, 6: $|8|-190$

42. Nyholm M, Gullberg B, Merlo J, Lundqvist-Persson C, Rastam L, Lindblad $U$ : The validity of obesity based on self-reported weight and height: Implications for population studies. Obesity 2007 I5:197-208

\section{Pre-publication history}

The pre-publication history for this paper can be accessed here:

\section{http://www.biomedcentral.com/1471-2458/8/165/pre} pub
Publish with Bio Med Central and every scientist can read your work free of charge

"BioMed Central will be the most significant development for disseminating the results of biomedical research in our lifetime. "

Sir Paul Nurse, Cancer Research UK

Your research papers will be:

- available free of charge to the entire biomedical community

- peer reviewed and published immediately upon acceptance

- cited in PubMed and archived on PubMed Central

- yours - you keep the copyright

Submit your manuscript here:

http://www.biomedcentral.com/info/publishing_adv.asp
BioMedcentral 